\title{
Apuntes sociológicos sobre los hermanos de la Sacramental de Santa Ana de Triana (1620-1709)
}

\author{
Sociological notes on the brothers of the \\ Sacramental of Saint Ana de Triana (1620-1709)
}

\author{
Amparo Rodríguez Babío \\ Biblioteca Benedicto XVI \\ Facultad de Teología San Isidoro de Sevilla \\ amparorbabio@gmail.com \\ ID ORCID 0000-0002-0803-688X
}

Resumen: La Hermandad del Santísimo Sacramento de la parroquia de Santa Ana de Triana fue fundada en 1540 por un grupo de clérigos vinculados a la misma. Muy pronto conoció un gran desarrollo debido a la entrada de gran número de feligreses que dejaron mandas y herencias para su sostenimiento. En el Archivo Parroquial se conserva un Libro de Hermanos que abarca de 1620 a 1709 , donde se recogen el nombre y otros datos de los hermanos existentes entre esas fechas. A través de los asientos de los mismos, se puede hacer una aproximación a la sociología no solo del barrio, sino también de la propia corporación.

Palabras clave: Hermandad Sacramental, Santa Ana, Triana, sociología

\begin{abstract}
The Brotherhood of the Holy Sacrament in the parish of Saint Ana de Triana was founded in 1540 by a group of clergymen linked to it. Sooner than later, it reached a great development due to the join of a huge amount of parishioners who donated legacies and inheritances to its sustenance. In the Parish Archive there is a Book of Brothers containing names and other details from the brothers who lived in between the years 1620 and 1709. Through the register of them, an approximation to the sociology not only of the neighbourhood, but also of the corporation itself can be done.
\end{abstract}

Keywords: Sacramental Brotherhood, Saint Ana, Triana, Sociology 


\section{LA HERMANDAD DEL SANTÍSIMO SACRAMENTO DE SANTA ANA DE TRIANA}

La Hermandad del Santísimo Sacramento de Santa Ana ${ }^{1}$ fue fundada en 1540 mediante una bula otorgada en Roma por el papa Paulo III a petición del clérigo Pedro de Espinosa. En efecto, el impulso fundador no partió como en otras ocasiones de los seglares o devotos, sino del propio clero parroquial. Hasta 1572 no fueron aprobados sus estatutos por la autoridad eclesiástica competente, lo que no fue óbice para que la corporación sacramental celebrase sus cultos y administrase su patrimonio.

Casi desde sus inicios contó la Hermandad con un buen número de donaciones, memorias y capellanías procedentes de hermanos y devotos. En el transcurso de los siglos llegaría a administrar unas 129 propiedades. Estas no eran sino el reflejo de un crecido censo, que llegó a alcanzar a finales del siglo XVII más de 500 hermanos.

Sometida a los vaivenes históricos, la corporación vivió su momento de máximo esplendor en el siglo XVIII, cuando se realizó por ejemplo, la actual custodia procesional. En la centuria siguiente, las epidemias, guerras y políticas desamortizadoras la sumieron en un profundo letargo, llegando casi a la inactividad total. Hacia 1940 se reorganiza a instancias de D. José María Arroyo Cera párroco de Santa Ana, volviendo a celebrar cultos y la procesión del Corpus Chico. En 1972 se fusionó con la Hermandad del Stmo. Cristo de las Tres Caídas y Ntra. Sra. de la Esperanza.

\section{EL LIBRO DE RECIBIMIENTO DE HERMANOS}

En el Archivo de Santa Ana se conserva buena parte, por no decir la totalidad, del perteneciente a la Sacramental. Entre los libros de cabildos, cuentas, protocolos, y legajos con los documentos relativos a su administración, sobresale un libro registro de hermanos ${ }^{2}$. De gran formato, encuadernado en pergamino, recoge 801 asientos de hermanos anotados entre 1620 y 1709. En la primera hoja aparece

\footnotetext{
1 Vid. para más información Amparo RODRÍGUEZ BABÍO, “Del origen y algunas noticias sobre la Hermandad del Santísimo Sacramento de la Real Parroquia de Santa Ana de Triana (Sevilla)", XII Simposio sobre Hermandades de Sevilla y su Provincia, Sevilla, 2011.

2 A(rchivo) R(eal) P(arroquia) S(anta) A(na) de T(riana), sign. 139/3.
} 
anotado con bella caligrafía: De la Cofradia del Ssmo. Sacra ${ }^{\text {to }}$ de Triana. Probablemente debió existir uno anterior que no ha llegado a nuestros días, que recogería sin duda, a la primera generación de cofrades de la Sacramental, aquellos inscritos entre 1540 (fecha de fundación de la corporación) y el primer tercio del siglo XVII. De hecho en algunos asientos se menciona un libro biejo, de cuya existencia no se dan más noticias.

El esquema de los asientos es sencillo: se anota el nombre del hermano, su fecha de ingreso, su oficio (no siempre), su fallecimiento y si pagó la averiguación o cuota. Aunque lo ideal era que cada folio correspondiera a un asiento, la práctica corriente era aprovechar el espacio, anotándose bajo el primero uno o incluso dos más. Se sigue siempre la misma fórmula: "N. entró por hermano de esta Cofradia el año...", con algunas variantes "N. se asentó por hermano de esta cofradía en..." o "N. se recibió por hermano de esta cofradía en...".

Se distinguen al menos tres caligrafías distintas, correspondientes sin duda, al escribano o secretario de cada periodo, que tenía entre sus tareas, apuntar a los hermanos nuevos, y cualquier incidencia relativa a los mismos.

Un estudio a fondo de los hermanos asentados en él nos permitirá conocer un poco más no sólo a la propia Hermandad Sacramental, sino también a los habitantes del barrio de Triana en los casi noventa años que abarca el Libro de Recibimientos.

\section{PERIODOS Y FECHAS DE INGRESO}

Un primer acercamiento correspondería a las fechas de recibimiento de hermanos por periodos de tiempo concreto de diez años. En la mayoría de los casos se anota además del año, el día y mes, lo que nos puede dar algunas ideas sobre la motivación de los cofrades para inscribirse: esplendor de los cultos externos, funciones religiosas solemnes, reacción ante epidemias o catástrofes naturales...

El asiento más antiguo consignado corresponde al año 1620, sin especificarse día ni mes, correspondiendo al hermano Francisco de Cangas; el más moderno es de agosto de 1709 asentándose al cofrade Joseph Navarro. En trece asientos no se anotó fecha alguna, quizás por despiste del secretario, o por pérdida de los datos de su recibimiento. 
En la tabla siguiente se ha contabilizado el total de hermanos divididos en décadas, a fin de estudiar la correspondencia entre periodos de mayor recibimiento y auge de la Hermandad.

\begin{tabular}{|c|c|}
\hline Década & $\begin{array}{c}\mathbf{N}^{\mathbf{o}} \text { de } \\
\text { recibimientos }\end{array}$ \\
\hline $1620-1630$ & 12 \\
\hline $1631-1640$ & 29 \\
\hline $1641-1650$ & 48 \\
\hline $1651-1660$ & 182 \\
\hline $1661-1670$ & 82 \\
\hline $1671-1680$ & 108 \\
\hline $1681-1690$ & 93 \\
\hline $1691-1700$ & 157 \\
\hline $1701-1709$ & 77 \\
\hline Sine data & 13 \\
\hline TOTAL & $\mathbf{8 0 1}$ \\
\hline
\end{tabular}

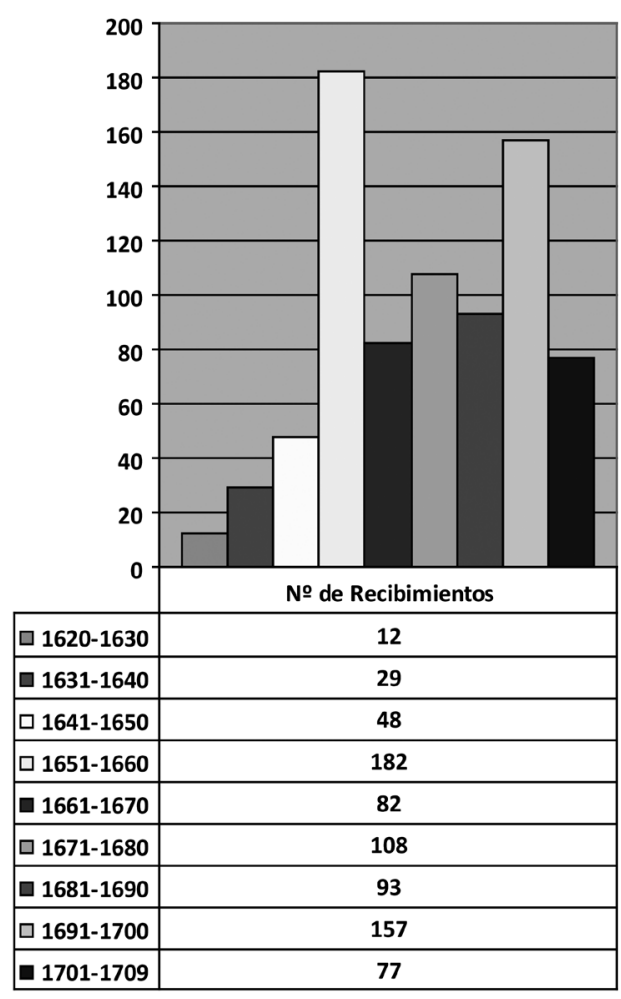

La primera década (1620-1630) recoge tan solo el ingreso de doce hermanos nuevos, lo que pudiera deberse a la existencia del anterior libro de asientos, hoy desaparecido. Para la siguiente (16311640) se constata un crecimiento de más del doble, proporción que se reduce un poco en la posterior (1641-1650). Llama la atención el grandísimo crecimiento experimentado en la década ulterior (16511660) en que los ingresos prácticamente se cuadruplican, una vez pasada la gran epidemia de peste bubónica de 1649. Para el periodo que sigue a continuación (1661-1670), se detecta una brusca bajada, quizás consecuencia de la subida anterior. Entre 1671 y 1680 volvemos a pasar del centenar de hermanos recibidos, para volver a disminuir 
un poco en los años 1681-1690. La recuperación se hace patente de nuevo en la década final que marca el paso de un siglo a otro (16911700), alcanzándose la cifra de 157 asientos. El último periodo abarca tan sólo nueve años, y se registraron 77 nuevos hermanos.

Una primera conclusión general que podemos sacar de esta estadística, es cómo en estos siglos centrales de la Edad Moderna, la devoción popular se concentraba en las que hoy denominamos hermandades sacramentales y letíficas. Y en efecto, a poco que se investigue en la historia de las cofradías de penitencia, se observa cómo en esta época, muchas de ellas tenían poca actividad, un menor número de hermanos, y en consecuencia menos ingresos, lo que se traducía en la imposibilidad de realizar la estación de penitencia la mayoría de las veces.

Las hermandades sacramentales sevillanas ${ }^{3}$, vinculadas a la parroquia de su collación, viven en estas centurias una edad de oro, que se traduce en la construcción de bellas capillas ornamentadas, ajuar litúrgico de plata, custodias procesionales... El elevado número de hermanos es causa de donaciones y de institución de capellanías y memorias, con lo que la mayoría de ellas llegó a administrar bastantes propiedades urbanas y rústicas.

En el caso de la Sacramental de Santa Ana, el aumento paulatino de ingresos de hermanos, se produce cuando la corporación lleva ya más de un siglo de existencia y está más que asentada en la collación. Además de los cultos internos, se celebraba desde sus inicios una procesión por las calles de Triana, conocida hoy como Corpus $\mathrm{Chico}^{4}$, cuyo boato nada tenía que envidiar a la organizada por el Cabildo Catedral. Estas vistosas ceremonias y el sentir devocional del momento, contribuyeron sin duda, al aumento de hermanos. Tampoco hay que menospreciar el caudal de gracias espirituales que ganaban los cofrades con su participación e inscripción en la hermandad. Todo ello contribuyó sin duda, a que se sobrepasase el centenar de altas en al menos tres décadas: 1651$1660,1671-1680$ y 1691-1700. En la primera de ellas, y a pesar de la

3 Vid. José RODA PEÑA, Hermandades sacramentales de Sevilla: una aproximación a su estudio, Sevilla, Guadalquivir, 1996.

4 Amparo RODRÍGUEZ BABÍO, "La procesión del Corpus de Triana (ss. XVIXVIII)", Anuario de Historia de la Iglesia andaluza, 5 (2012) 357-378. 
gran mortandad ${ }^{5}$ provocada por la peste de 1649 , se alcanzó la cifra de 182 hermanos. Quizás el sufrimiento y las penalidades causados por la enfermedad, dieron paso a una conversión y a una vivencia de la fe cristiana más profunda, reflejados en su adscripción a una cofradía.

Aunque para la Edad Moderna no hay datos fidedignos en cuanto a número de habitantes, los contenidos en dos censos conservados nos pueden ofrecer una cifra aproximada de los moradores de Sevilla. Se trata de dos padrones realizados en 1588 y 1655, estudiados en su día por el insigne D. Antonio Domínguez Ortiz ${ }^{6}$, del cual comentaremos los datos referidos a Triana. Así si en la collación se contabilizaban 15.520 personas en 1588, en 1655 tan sólo seis años después de la epidemia de 1649, los habitantes de Triana habían quedado reducidos a 5.172, es decir habían mermado en una tercera parte.

Entre 1671 y 1680 se asentaron 108 hermanos nuevos, muchos de los cuales estaban relacionados con el comercio marítimo, o las industrias anejas a la construcción y mantenimiento de navíos. También se constata la presencia de clérigos de la parroquia de Santa Ana entre los recibimientos. Durante el periodo colonial español, en Triana debió existir una población flotante de cierto calado, que iba y venía a las Indias, lo que explica la concentración de personas adscritas al arte de la mar.

Para el último periodo destacado se alcanzó una cifra de 157 ingresos, lo que sin duda está relacionado con la recuperación económica que vivió la ciudad en esos años finales del siglo XVII. Bonanza que duraría bien poco pues en 1709 una nueva epidemia diezmaría la ciudad, y unos años después en 1717 el rey Carlos III firmaría la sentencia de muerte de Sevilla, y por ende, de Triana, al trasladar la Casa de Contratación a Cádiz.

Se dice que sólo en Triana perecieron 12.000 personas. Vid. Copiosa relacion de lo sucedido en el tiempo que duro la epidemia en la grande y augustissima ciudad de Seuilla, año de 1649, Impresso en Ezija por Iuan Malpartida de las Alas, 1649.

6 Antonio DOMÍNGUEZ ORTÍZ, "La población de Sevilla a mediados del siglo XVII", Archivo Hispalense, 221 (1989) 3-15. 


\section{PROFESIONES Y OFICIOS ENTRE LOS HERMANOS DE LA SACRAMENTAL DE SANTA ANA}

Del total de asientos consignados (801), tan sólo se anota el oficio del hermano en 300 casos. A pesar de todo, podemos extraer una muestra del tejido social y económico del barrio de Triana en este periodo que estudiamos.

\begin{tabular}{|c|c|}
\hline Profesión / Oficio & Número \\
\hline Abogado & 1 \\
\hline Administrador del voto de Santiago & 1 \\
\hline Albañil & 1 \\
\hline Alcaide de la cárcel secreta de la Inquisición & 1 \\
\hline Alférez & 1 \\
\hline Alguacil de Triana & 1 \\
\hline Arráez del pasaje & 1 \\
\hline Arráez del río & 4 \\
\hline Arriero de vino & 1 \\
\hline Ayudante de piloto & 1 \\
\hline Bachiller & 1 \\
\hline Barbero & 1 \\
\hline Beneficiado & 2 \\
\hline Caballero veinticuatro de la ciudad & 2 \\
\hline Caballero del hábito de Santiago & 1 \\
\hline Calafate & 17 \\
\hline Capellán de Santa Ana & 2 \\
\hline Capellán del Santo Oficio & 1 \\
\hline Capitán & 42 \\
\hline Carpintero & 4 \\
\hline Carpintero de ribera & 14 \\
\hline Caudalero de ladrillo & 1 \\
\hline Caudalero de loza & 1 \\
\hline Caudalero de loza fina & 1 \\
\hline Caudalero de yeso & 1 \\
\hline Cerero & 1 \\
\hline Cerrajero & 1 \\
\hline Cirujano & 1 \\
\hline Clérigo de menores & 7 \\
\hline Clérigo diácono & 2 \\
\hline Confitero & 3 \\
\hline Contramaestre & 11 \\
\hline Crucero de Santa Ana & 1 \\
\hline Cura de Santa Ana & 5 \\
\hline Del arte de la mar & 2 \\
\hline
\end{tabular}




\begin{tabular}{|c|c|}
\hline Profesión / Oficio & Número \\
\hline De la Orden del Espíritu Santo & 1 \\
\hline Diácono de Santa Ana & 1 \\
\hline Doctor beneficiado y cura de Santa Ana & 1 \\
\hline Doctor médico & 3 \\
\hline Escribano del Santo Oficio & 1 \\
\hline Escribano público & 3 \\
\hline Escribano real & 1 \\
\hline Espartero & 3 \\
\hline Estudiantes & 2 \\
\hline Familiar del Santo Oficio & 4 \\
\hline Fraile & 1 \\
\hline Fraile del Espíritu Santo & 1 \\
\hline Guarda Mayor de la Barqueta de la Sal & 1 \\
\hline Herrador & 2 \\
\hline Herrero & 1 \\
\hline Jurado & 3 \\
\hline Jurado de Sevilla & 1 \\
\hline Licenciado & 14 \\
\hline Licenciado Cirujano & 1 \\
\hline Licenciado cura de Santa Ana & 1 \\
\hline Licenciado diácono & 1 \\
\hline Licenciado presbítero & 14 \\
\hline Licenciado sochantre de Santa Ana & 1 \\
\hline Licenciado vicenuncio del Santo Oficio & 1 \\
\hline Licenciado y capellán de Santa Ana & 2 \\
\hline Licenciado subdiácono y capellán de Santa Ana & 2 \\
\hline Maestro albañil & 1 \\
\hline Maestro albardonero & 1 \\
\hline Maestro barbero & 4 \\
\hline Maestro boticario & 1 \\
\hline Maestro calafate & 1 \\
\hline Maestro carpintero & 2 \\
\hline Maestro cerrajero & 1 \\
\hline Maestro cirujano & 2 \\
\hline Maestro cordonero & 1 \\
\hline Maestro albañil & 1 \\
\hline Maestro alfarero & 1 \\
\hline Maestro de escuela & 2 \\
\hline Maestro zapatero & 3 \\
\hline Maestro del barro & 1 \\
\hline Maestro espadero & 1 \\
\hline Maestro guarnicionero & 1 \\
\hline Maestro herrador & 1 \\
\hline
\end{tabular}




\begin{tabular}{|c|c|}
\hline Profesión / Oficio & Número \\
\hline Maestro herrero & 1 \\
\hline Maestro mayor de calafate & 1 \\
\hline Maestro sastre & 2 \\
\hline Maestro sombrerero & 1 \\
\hline Maestro tornero & 1 \\
\hline Navegante & 4 \\
\hline Notario de la Audiencia Arzobispal & 1 \\
\hline Notario del Santo Oficio & 4 \\
\hline Oficial de botijero & 1 \\
\hline Panadero & 2 \\
\hline Piloto & 6 \\
\hline Piloto del río & 1 \\
\hline Piloto Mayor de Galeones & 1 \\
\hline Pintor de loza & 2 \\
\hline Presbítero & 12 \\
\hline Presbítero beneficiado de Santa Ana & 3 \\
\hline Prior del Espíritu Santo & 2 \\
\hline Sargento & 2 \\
\hline Sargento Mayor & 4 \\
\hline Sastre & 1 \\
\hline Secretario del fisco de la Inquisición & 1 \\
\hline Secretario del Santo Oficio & 6 \\
\hline Secretario más antiguo del Secreto del Santo Oficio & 1 \\
\hline Semillero & 1 \\
\hline Sombrerero & 1 \\
\hline Tintorero & 1 \\
\hline Tornero & 1 \\
\hline Tratante en ir a Cádiz con su gabarra & 1 \\
\hline Visitador de las fábricas de Sevilla & 1 \\
\hline Zapatero & 2 \\
\hline
\end{tabular}

Podemos organizar la información en grandes grupos profesionales cuyo análisis nos mostrará a su vez la distribución sociológica de los mismos y su mayor o menor influencia en la collación:

\section{Administración pública}

De los 300 hermanos cuyos oficios se consignan tan sólo 13 trabajaban para la administración pública, entendiéndose esta en un sentido amplio del término. Así encontramos en este grupo un abogado, un alguacil, cuatro jurados, cuatro escribanos, el Guarda Mayor de la Barqueta de la Sal y dos caballeros veinticuatro. Alguaciles y jurados 
constituían la cara más visible de la administración ciudadana, puesto que debían hacer cumplir los acuerdos del Cabildo Municipal. El Alguacil Mayor tenía a su cargo veinte alguaciles repartidos por cada collación que le auxiliaban en su labor. En cuanto a los jurados funcionaban como una suerte de representación popular de los habitantes de la collación, y su número varió según las épocas. En el Libro de Asientos se anotaron cuatro, aunque de uno de ellos se concreta de Sevilla, por lo que debemos suponer que los tres restantes lo eran de Triana. Los escribanos se encontraban también entre los oficios representados entre los hermanos de la Sacramental: son cuatro en total, tres de ellos públicos, y uno de ellos real, llamados así por haber recibido su nombramiento del rey y no del Cabildo Municipal. El Guarda Mayor de la Barqueta de la Sal puede ser un cargo relacionado con el monopolio de este producto, cuyo depósito hoy desaparecido se alzaba en la calle Almirantazgo.

Justino Matute se hace eco de este aspecto, con estas expresivas palabras, remarcando la singularidad de una collación a la que separaba el río, no sólo física, sino también mentalmente del resto de Sevilla: "No obstante que Triana sea una con Sevilla, la distancia que media entre ambas poblaciones, y la autoridad que le han ganado sus ilustres establecimientos le han proporcionado que se le considere con cierta superioridad de que carecen las demás parroquias. [...] La Real jurisdicción la ha desempeñado un alcalde mayor con el título de Teniente tercero, señalado por S. M. para este barrio, igual en autoridad a los de Sevilla, quien ha vivido en Triana, y tenido en ella muchas veces su juzgado. Para su servicio y demás que pueda ocurrir en este barrio hay un alguacil denominado de Triana"7. Los jurados como era común en la época"eran nombrados por los vecinos de las mismas [collaciones] y elegidos entre los más distinguidos feligreses" lo que parece deducirse de el título "don" antepuesto al nombre de Baltasar Bonifaz y Miranda, inscrito en el Libro de Hermanos el 14 de mayo de 1676.

\footnotetext{
7 Justino MATUTE Y GAVIRIA, Aparato para escribir la historia de Triana y de su iglesia parroquial, Sevilla, Sociedad de Bibliófilos Andaluces, 1977, 134.

8 MATUTE, Aparato, 137.
} 


\begin{tabular}{|c|l|c|}
\hline Administración pública & Abogado & 1 \\
\hline Administración pública & Alguacil de Triana & 1 \\
\hline Administración pública & $\begin{array}{l}\text { Caballero veinticuatro de } \\
\text { la ciudad }\end{array}$ & 2 \\
\hline Administración pública & Escribano público & 3 \\
\hline Administración pública & Escribano real & 1 \\
\hline Administración pública & $\begin{array}{l}\text { Guarda Mayor de la } \\
\text { Barqueta de la Sal }\end{array}$ & 1 \\
\hline Administración pública & Jurado & 3 \\
\hline Administración pública & Jurado de Sevilla & $\mathbf{1 3}$ \\
\hline
\end{tabular}

\section{Artesanos}

En este grupo hemos contabilizado aquellos oficios manuales útiles y necesarios para la vida diaria: cereros, zapateros, herradores, sastres... En dieciséis de los casos aparecen denominados como "maestro", lo que indica un rango superior dentro del taller o tienda: albardonero, cerrajero, cordonero, alfarero, zapatero, espadero, guarnicionero, herrador, herrero, sastre, sombrerero, tintorero y tornero, que nos indican la vida plena en una collación con todo su bullicio y afanes. Matute que para la redacción de su libro, consultó e investigó en los archivos parroquiales e históricos, comentaba al respecto que en Triana se concentraban"muchos almacenes y lonjas donde se halla cuanto es cómodo y necesario a la vida" ${ }^{\prime \prime}$, lo que en parte, queda patente en el muestrario de comerciantes y artesanos aquí reseñados. De Tomás Mendes, tintorero, que ingresó en la Hermandad en 1653, se anota en su partida que ocupó el cargo de prioste desde 1663 hasta 1669.

En un solo caso el hermano se denomina" oficial" de botijero, llamando la atención que pese a la importancia de la alfarería en Triana, tan sólo haya cinco hermanos del gremio: dos maestros alfareros y del barro, un oficial botijero y dos pintores de loza.

9 MATUTE, Aparato, 135. 


\begin{tabular}{|c|c|c|}
\hline Artesanos & Cerero & 1 \\
\hline Artesanos & Cerrajero & 1 \\
\hline Artesanos & Espartero & 3 \\
\hline Artesanos & Herrador & 2 \\
\hline Artesanos & Herrero & 1 \\
\hline Artesanos & Maestro albardonero & 1 \\
\hline Artesanos & Maestro cerrajero & 1 \\
\hline Artesanos & Maestro cordonero & 1 \\
\hline Artesanos & Maestro alfarero & 1 \\
\hline Artesanos & Maestro zapatero & 3 \\
\hline Artesanos & Maestro del barro & 1 \\
\hline Artesanos & Maestro espadero & 1 \\
\hline Artesanos & Maestro guarnicionero & 1 \\
\hline Artesanos & Maestro herrador & 1 \\
\hline Artesanos & Maestro herrero & 1 \\
\hline Artesanos & Maestro sastre & 2 \\
\hline Artesanos & Maestro sombrerero & 1 \\
\hline Artesanos & Maestro tornero & 1 \\
\hline Artesanos & Oficial de botijero & 1 \\
\hline Artesanos & Pintor de loza & 2 \\
\hline Artesanos & Sastre & 1 \\
\hline Artesanos & Semillero & 1 \\
\hline Artesanos & Sombrerero & 1 \\
\hline Artesanos & Tintorero & 1 \\
\hline Artesanos & Tornero & 1 \\
\hline \multirow[t]{2}{*}{ Artesanos } & Zapatero & 2 \\
\hline & TOTAL & 34 \\
\hline
\end{tabular}

\section{Clero regular y secular}

La parroquia de Santa Ana contó siempre con un lugar destacado entre las sevillanas, pues por su número y antigüedad"su cruz parroquial preside en las procesiones y concurrencias públicas a las demás, 
exceptuando sólo la del Salvador"10. El numeroso clero que la servía desde antaño, llegó a fundar una hermandad de sacerdotes bajo el patrocinio de San Joaquín en $1628^{11}$, contándose en ese momento cuarenta y dos clérigos en la parroquia. Por otra parte, la vinculación de Santa Ana con la Hermandad Sacramental se remontaba a sus orígenes ${ }^{12}$ : había sido fundada por el clero parroquial y la mitad de sus oficios, debían estar ocupados por estos.

También aparecen registrados cinco religiosos del convento del Espíritu Santo, institución hoy desaparecida que ocupaba el tramo final de la calle Pureza. Uno de ellos, el prior Gregorio Núñez Salguero, es asentado en razón de la pertenencia a la corporación de su padre, capitán del mismo nombre, anotándose en su asiento fechado el 1 de julio de 1696,"por ser hijo de hermano".

El presbítero beneficiado Pedro Larios Monge ingresó en la Hermandad en 1634 y una breve nota de su vida aparece recogida en la obra ya mencionada de Matute:"abad mayor de la universidad de Beneficiados, y beneficiado propio de Santa Ana, nació por los años de 1599, hijo de Cristóbal García y de Mariana Macías, su mujer, hermano de aquel Dr. Larios, de quien acabamos de hablar. Mereció igual concepto que su tío, y fue muy estimado"13.

\begin{tabular}{|l|l|l|}
\hline Clero & Administrador del voto de Santiago & 1 \\
\hline Clero & Alcaide de la cárcel secreta de la Inquisición & 1 \\
\hline Clero & Beneficiado & 2 \\
\hline Clero & Capellán de Santa Ana & 2 \\
\hline Clero & Capellán del Santo Oficio & 1 \\
\hline Clero & Clérigo de menores & 7 \\
\hline Clero & Clérigo diácono & 2 \\
\hline Clero & Crucero de Santa Ana & 1 \\
\hline Clero & Cura de Santa Ana & 5 \\
\hline
\end{tabular}

10 MATUTE, Aparato, 34.

11 Amparo RODRÍGUEZ BABÍO, “La Hermandad de Sacerdotes de San Joaquín de la parroquia de Santa Ana de Sevilla (Ss. XVII-XVIII)", Anuario de Historia de la Iglesia andaluza 6 (2013) 365-380.

12 Amparo RODRÍGUEZ BABÍO,“Del origen y algunas noticias sobre la Hermandad del Santísimo Sacramento de la Real Parroquia de Santa Ana de Triana (Sevilla)", XII Simposio sobre Hermandades de Sevilla y su Provincia, Sevilla, 2011, 15-46.

13 MATUTE, Aparato, 55. 


\begin{tabular}{|l|l|c|}
\hline Clero & De la Orden del Espíritu Santo & 1 \\
\hline Clero & Diácono de Santa Ana & 1 \\
\hline Clero & Doctor beneficiado y cura de Santa Ana & 1 \\
\hline Clero & Fraile & 1 \\
\hline Clero & Fraile del Espíritu Santo & 1 \\
\hline Clero & Licenciado cura de Santa Ana & 1 \\
\hline Clero & Licenciado diácono & 1 \\
\hline Clero & Licenciado presbítero & 14 \\
\hline Clero & Licenciado sochantre de Santa Ana & 1 \\
\hline Clero & Licenciado y capellán de Santa Ana & 2 \\
\hline Clero & Licenciado subdiácono y capellán de Santa Ana & 2 \\
\hline Clero & Notario de la Audiencia Arzobispal & 1 \\
\hline Clero & Presbítero & 12 \\
\hline Clero & Presbítero beneficiado de Santa Ana & 3 \\
\hline Clero & Prior del Espíritu Santo & 2 \\
\hline Clero & Visitador de las fábricas de Sevilla & 1 \\
\hline & TOTAL & $\mathbf{6 7}$ \\
\hline
\end{tabular}

\section{Comerciantes y tratantes}

Ya hemos comentado más arriba que la collación trianera se articulaba en razón de su peculiaridad como una especie de ciudad paralela, idiosincrasia que se acentuó a raíz del Descubrimiento de América y la afluencia de comerciantes, mercaderes y tratantes. El río, vía principal de la entrada y salida de mercancías, duplicó su tráfico al aumentar también la población de Sevilla en general.

Así encontramos a once hermanos de la Sacramental cuyo oficio era precisamente el comerciar y transportar diversos géneros. Caudaleros eran llamados los almacenistas o comerciantes relacionados con la alfarería y los barros vidriados; ladrillos, loza, loza fina y yeso, eran las materias con las que trataban.

Otro oficio relacionado con el tráfico fluvial era el de arráez, que no es más que el capitán o jefe de una gabarra ${ }^{14}$. En este caso dos de ellos debían dedicarse al paso de personas o pequeñas mercancías de una orilla a otra del río (arráez del pasaje, del río), otro estaba

14 RAE: "barco pequeño y chato destinado a la carga y descarga en los puertos". 
especializado en vino y el tercero, especifica que realizaba la ruta a Cádiz.

\begin{tabular}{|l|l|c|}
\hline Comerciantes y tratantes & Caudalero de ladrillo & 1 \\
\hline Comerciantes y tratantes & Caudalero de loza & 1 \\
\hline Comerciantes y tratantes & Caudalero de loza fina & 1 \\
\hline Comerciantes y tratantes & Caudalero de yeso & 1 \\
\hline Comerciantes y tratantes & $\begin{array}{l}\text { Tratante en ir a Cádiz con su } \\
\text { gabarra }\end{array}$ & 1 \\
\hline Comerciantes y tratantes & Arráez del pasaje & 1 \\
\hline Comerciantes y tratantes & Arráez del río & 4 \\
\hline Comerciantes y tratantes & Arriero de vino & 1 \\
\hline & TOTAL & $\mathbf{1 1}$ \\
\hline
\end{tabular}

\section{Construcción}

En este apartado hemos consignado a aquellos hermanos relacionados con la edificación y reparación de viviendas. Como en otras ocasiones hay una diferenciación de rango y categoría laboral entre los simples carpinteros y albañil y los cuatro maestros que se consignan, reflejo de la organización gremial que perviviría en la sociedad hasta bien entrado el siglo XVIII.

Como curiosidad en el asiento del maestro carpintero Manuel Martínez, fechado en 1690, se anotó lo siguiente "pagó su entrada con una limosna que hizo en las obras de la Casa de Hermandad", práctica que en cierto modo, sigue vigente entre las numerosas cofradías existentes en Sevilla.

\begin{tabular}{|l|l|l|}
\hline Construcción & Albañil & 1 \\
\hline Construcción & Carpintero & 4 \\
\hline Construcción & Maestro carpintero & 2 \\
\hline Construcción & Maestro albañil & 2 \\
\hline & TOTAL & $\mathbf{9}$ \\
\hline
\end{tabular}

\section{Indeterminado}

Si bien el Libro de Hermanos es bastante completo en la mayoría de los asientos analizados, hay dieciocho casos en los que la simple 
mención del oficio u ocupación apenas nos da idea de la misma. Es el caso de estos bachiller, estudiantes y licenciados de los que desconocemos si eran laicos o eclesiásticos. Del caballero del hábito de Santiago solo se nos notifica la pertenencia a la orden militar sin Conocer si además ocupaba algún cargo administrativo.

\begin{tabular}{|l|l|c|}
\hline Indeterminado & Bachiller & 1 \\
\hline Indeterminado & Caballero del hábito de Santiago & 1 \\
\hline Indeterminado & Estudiantes & 2 \\
\hline Indeterminado & Licenciado & 14 \\
\hline & TOTAL & $\mathbf{1 8}$ \\
\hline
\end{tabular}

\section{Medicina}

Al área médico-sanitaria pertenecían ocho miembros, encontrando entre ellos a cuatro cirujanos, tres doctores y un boticario, buena muestra de la numerosa población que habitaba Triana donde encontrarían su clientela.

\begin{tabular}{|l|l|l|}
\hline Medicina & Cirujano & 1 \\
\hline Medicina & Doctor médico & 3 \\
\hline Medicina & Licenciado Cirujano & 1 \\
\hline Medicina & Maestro boticario & 1 \\
\hline Medicina & Maestro cirujano & 2 \\
\hline & TOTAL & $\mathbf{8}$ \\
\hline
\end{tabular}

\section{Militares}

De la milicia sólo hayamos siete representantes en los censos de la corporación, con las graduaciones de alférez y sargento. Ninguna información más podemos añadir sobre ellos, tan sólo que debían vivir en Triana y pertenecer sin duda a la feligresía de Santa Ana.

\begin{tabular}{|l|l|l|}
\hline Militares & Alférez & 1 \\
\hline Militares & Sargento & 2 \\
\hline Militares & Sargento Mayor & 4 \\
\hline & TOTAL & 7 \\
\hline
\end{tabular}




\section{Oficios de la mar}

De todos los hermanos registrados cuyos oficios se anota, es éste el grupo más numeroso con diferencia, alcanzando la cifra de 102. Es lógica toda esta abundancia de gente relacionada con los oficios de la mar, toda vez que como antes se ha mencionado, tras el Descubrimiento de América, todo el tráfico fluvial y con las Indias, quedó centralizado en la "guarda y collación de Sevilla". Así lo comentaba también Matute en su célebre obra "la más gruesa parte de su vecindario la componían gentes dedicadas a los egercicios de la mar [...]. Quien más bulle en ella, dice el citado Morgado, es toda la gente de mar, como son capitanes, pilotos, maestres y toda suerte de marineros" ${ }^{\prime 15}$. Así se consignan nada menos que 42 capitanes, 11 contramaestres y 7 pilotos. Mención aparte merece el Piloto Mayor de Galeones, Gabriel de Barros ${ }^{16}$ asentado en 1655. Nacido hacia 1595 en la isla de la Palma (Canarias), llega a Triana hacia 1620, donde contrae matrimonio con María de Saavedra. En 1644 es nombrado merced a su experiencia y buen hacer en el navegar, Piloto Mayor de la flota de Nueva España. Hija suya fue Josefa de Barros, que en 1680 fundaría la Hermandad de la Pura y Limpia en Santa Ana.

Otro de los hermanos cuyo oficio era el de capitán, Jacinto Núñez de Luarca asentado como hermano en 1667, es citado por Matute al referir la historia del convento dominico de San Jacinto. Núñez de Luarca estaba enterrado al pie del altar de Ntra. Sra. del Rosario de la que era devoto ${ }^{17}$. De otro de ellos, Manuel Gómez que ingresó en 1662, se anota en su asiento que"dio de limosna una campanilla de plata que pesó 70 pesos para quando sale el Ssmo. Sacramento a los enfermos".

Hemos incluido en este epígrafe a los carpinteros de ribera y calafates, pues su actividad estaba íntimamente relacionada con el navegar de barcos de todo tipo, ya que el astillero estaba establecido en la collación, en las cercanías del convento de los Remedios: "el astillero de la marina mercante estaba establecido en Triana en el campo de los Remedios, donde de antiguo se veneraba una imagen

\footnotetext{
15 MATUTE, Aparato, 138.

16 Amparo RODRÍGUEZ BABÍO, "Doña Josefa de Barros, fundadora de la Hermandad de la Pura y Limpia Concepción de Santa Ana (Triana)", Anuario de Historia de la Iglesia andaluza 8 (2015), 321-338.

17 MATUTE, Aparato, 99-100.
} 
de Ntra. Sra. que dio origen al inmediato convento, que lleva su título, según queda advertido. [...] De aquí otras cofradías y memorias, muchas capellanías y dotaciones, y gran número de nobles edificios, que hermoseaban las calles de esta collación"18. Toda esta bonanza económica se perdió cuando se trasladó la Casa de Contratación a Cádiz, circunstancia que el propio autor apunta como la principal de la devaluación de Triana: "Sus principales casas [...] se han ido arruinando a proporción que se disminuía el comercio exclusivo con América. [...] Pero así como debió Triana su opulencia al descubrimiento de América, en que sus naves conducían a las playas andaluzas los tesoros de aquellas minas, luego que el comerció faltó de esta Ciudad, se disminuyó considerablemente su población"19.

\begin{tabular}{|l|l|c|}
\hline Oficios de la mar & Ayudante de piloto & 1 \\
\hline Oficios de la mar & Calafate & 17 \\
\hline Oficios de la mar & Capitán & 42 \\
\hline Oficios de la mar & Carpintero de ribera & 14 \\
\hline Oficios de la mar & Contramaestre & 11 \\
\hline Oficios de la mar & Del arte de la mar & 2 \\
\hline Oficios de la mar & Maestro calafate & 1 \\
\hline Oficios de la mar & Maestro mayor de calafate & 1 \\
\hline Oficios de la mar & Navegante & 4 \\
\hline Oficios de la mar & Piloto & 6 \\
\hline Oficios de la mar & Piloto del río & 1 \\
\hline Oficios de la mar & Piloto Mayor de Galeones & 1 \\
\hline & TOTAL & $\mathbf{1 0 2}$ \\
\hline
\end{tabular}

\section{Santo Oficio}

Creada la Santa Inquisición por la reina Isabel I de Castilla en 1478, quedó establecida su sede en el castillo de San Jorge de Triana. Esto supuso que gran parte de los oficiales y familiares que trabajaban en ella, tuviesen su residencia en Triana, lo que se muestra en los dieciocho hermanos de la Sacramental. Entre ellos hay escribanos, familiares (laicos que colaboraban con el Santo Oficio), notarios (uno

19 MATUTE, Aparato, 135-136. 
de ellos denominado del secreto era encargado de anotar las declaraciones de los acusados) y un licenciado vicenuncio. Uno de los secretarios, Laureano Bejarano Infante, hermano desde 1648, falleció en 1664 siendo mayordomo de la corporación, según reza una anotación en su partida.

\begin{tabular}{|l|l|c|}
\hline Santo Oficio & Escribano del Santo Oficio & 1 \\
\hline Santo Oficio & Familiar del Santo Oficio & 4 \\
\hline Santo Oficio & Licenciado vicenuncio del Santo Oficio & 1 \\
\hline Santo Oficio & Notario del Santo Oficio & 4 \\
\hline Santo Oficio & Secretario del fisco de la Inquisición & 1 \\
\hline Santo Oficio & Secretario del Santo Oficio & 6 \\
\hline Santo Oficio & $\begin{array}{l}\text { Secretario más antiguo del Secreto del } \\
\text { Santo Oficio }\end{array}$ & 1 \\
\hline & TOTAL & $\mathbf{1 8}$ \\
\hline
\end{tabular}

\section{Sector servicios}

En este apartado se han consignado aquellas actividades relacionadas con los servicios, bien alimentarios (confitería, panadería), bien educativos (maestro de escuela) o de aseo personal (maestro barbero). Esto nos da también idea de la mezcolanza social que se podía encontrar en una hermandad, realidad extrapolable a otras de la ciudad. Unidos por la devoción al Santísimo Sacramento y por su vecindad en la collación, se pone aquí de manifiesto una de las características de la habitabilidad en ciudades del Ancien Régime, la convivencia estrecha entre diversas capas sociales en una misma zona, y su interrelación en estos espacios sagrados.

\begin{tabular}{|l|l|c|}
\hline Sector servicios & Barbero & 1 \\
\hline Sector servicios & Confitero & 3 \\
\hline Sector servicios & Maestro barbero & 4 \\
\hline Sector servicios & Maestro de escuela & 2 \\
\hline Sector servicios & Panadero & 2 \\
\hline & TOTAL & $\mathbf{1 2}$ \\
\hline
\end{tabular}




\section{CONCLUSIONES}

La visión que el imaginario popular tiene del barrio de Triana como un lugar de arte, flamencos, toreros y cigarreras nacida en el Romanticismo y popularizada por viajeros ingleses y franceses, ensombrece en cierto modo la rica y desconocida historia de la guarda y collación de Sevilla. Hasta el siglo XIX en que las circunstancias políticas, históricas y epidémicas devaluaron la economía y la población del barrio, Triana era una collación más, con una organización similar a las de la ciudad, con la única particularidad de la frontera natural del río Guadalquivir. En los siglos que nos ocupan, XVII y principios del XVIII, la característica de Triana era la abundante población dedicada a la navegación, bien directamente (capitanes, contramaestres, marineros, mercaderes, armadores), bien indirectamente (calafates, astilleros, carpinteros de ribera). Algunos de estos alcanzaron un status social elevado, lo que se deduce de las muchas dotaciones y capellanías que dejaron fundadas para la Hermandad Sacramental en Santa Ana y en algunos conventos de la zona. La Casa de Contratación y el Colegio de Mareantes de San Telmo, venían a reforzar el carácter marinero de esta orilla del Guadalquivir.

La presencia del tribunal de la Inquisición y sus oficiales, le dotaba además de la presencia de esta"nobleza de toga"de administradores, escribanos y notarios. A estos dos grupos principales se unía el del numeroso clero que pululaba no solo por la parroquia de Santa Ana, sino también en los conventos de San Francisco de Paula, San Jacinto y de los Remedios. A estos estamentos se unía la variopinta masa del pueblo: artesanos, agricultores (de los que no tenemos muestra conocida en la Sacramental), alfareros, boticarios, barberos, sastres... que en la Hermandad encontraban un modo de relacionarse con esos estratos más elevados. La asistencia a los cultos, la preparación de altares, fiestas y reuniones se presentaban, pues, como un modo de articular las relaciones inter clases dentro de los parámetros de una sociedad teóricamente rígida. 


\section{Profesiones y oficios entre los hermanos de} la Sacramental de Santa Ana de Triana



$\square$ Administración

$\square$ Artesanos

$\square$ Clero

$\square$ Comerciantes

$\square$ Construcción

$\square$ Indeterminado

$\square$ Medicina

$\square$ Militares

口 Oficios de la mar

$\square$ Santo Oficio

$\square$ Servicios 


\section{ILUSTRACIONES}

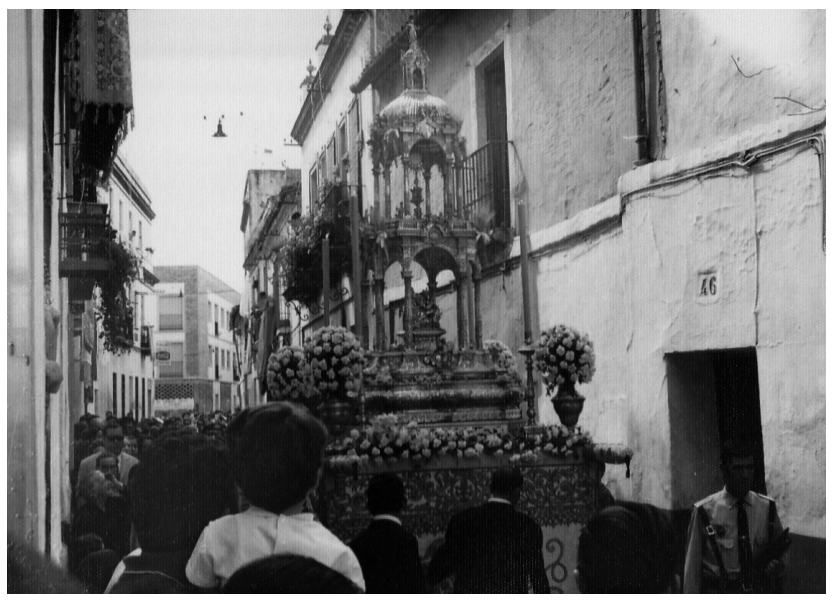

Corpus Chico: Custodia de la Sacramental en la procesión del Corpus de 1969 (foto: A. Rodríguez Curquejo)

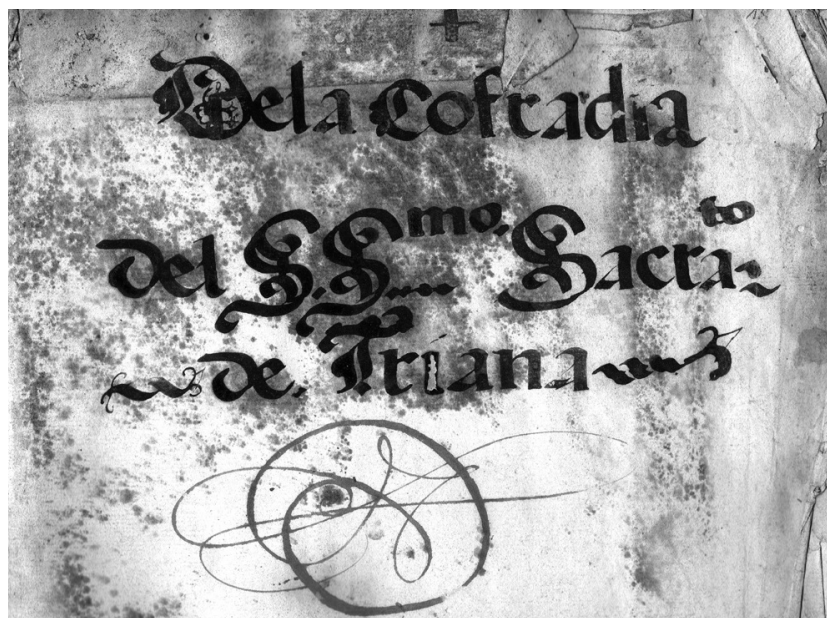

Portada del Libro de Hermanos 


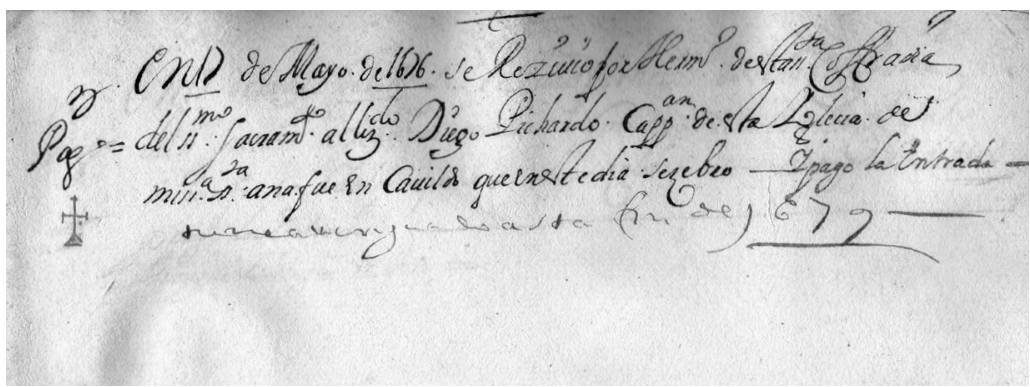

Asiento de un hermano con diversas anotaciones

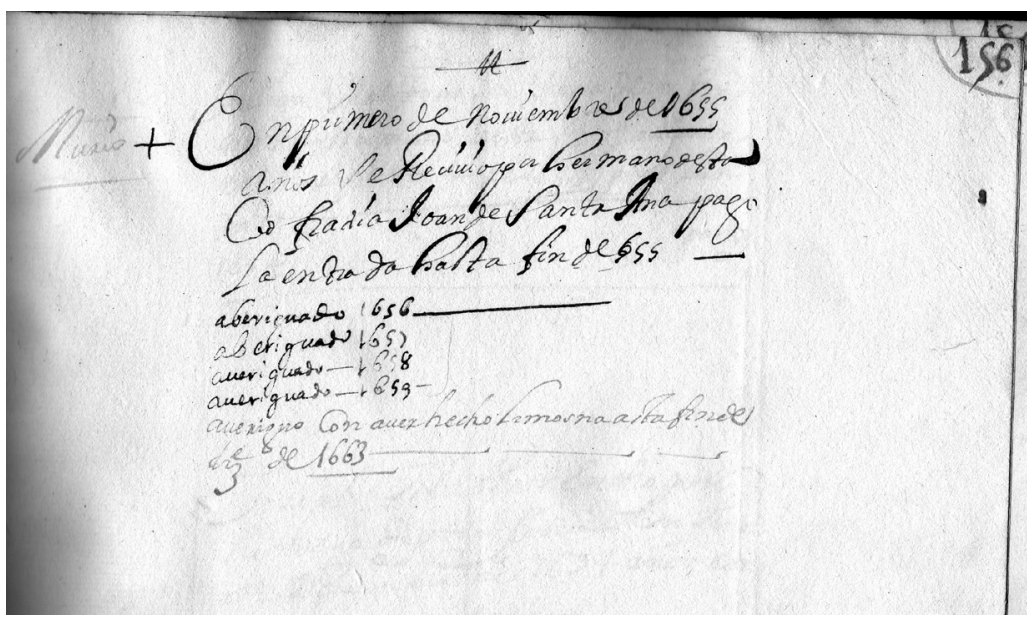

Asiento con notas de haber averiguado o pagado la cuota

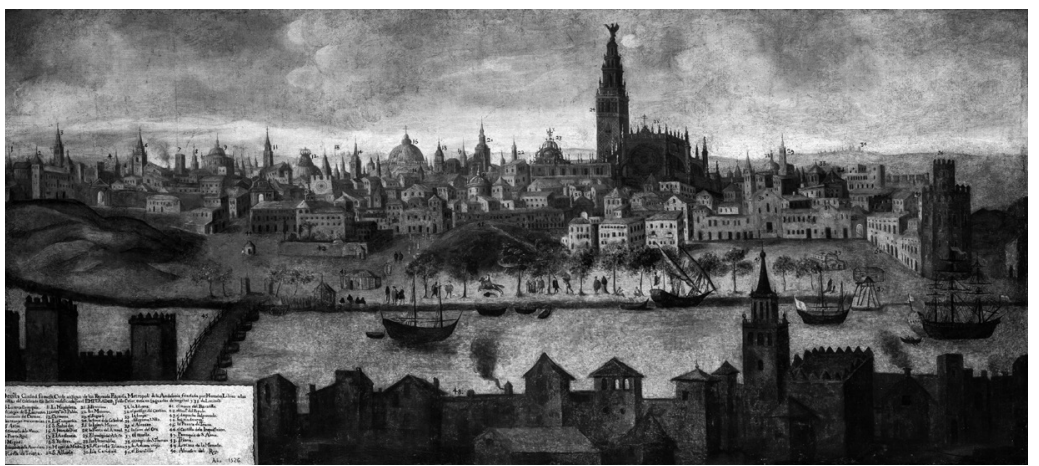

Vista de Triana y de Sevilla (Ayuntamiento de Sevilla) 
